\title{
Customizing Instruction
}

\section{Frank Kurzel \\ University of South Australia, Adelaide, Australia}

\author{
Frank.Kurzel@unisa.edu.au
}

\begin{abstract}
In this paper, we examine techniques employed to customize features within an information technology related leaning environment. Fine grained concepts form the basis of the system; these are initially configured hierarchically into sessions by the instructor to constitute a week's worth of work. Tools however, exist to provide other forms of access. This constitutes a separation of the course's knowledge and skill base from the instructional methodology pursued. A session for example, is an instructor driven grouping that has instructional significance. Other instructional objects or artifacts that play particular roles in a methodology can be specified. We examine a problem based scenario and contrast it with an expository form of delivery.

Adaptive hypermedia techniques driven by student profiling, are employed to provide students with feedback on their status with particular concepts. Students have access to all course metadata through a range of tools, along with web based tools to scrutinize and access information stored about them. This also includes the formal assessment maintained for the course and any individual settings used by the environment.
\end{abstract}

Keywords: learning environments, customization, instruction, course metadata, student profiles.

\section{Introduction}

Improving Learning Environments (LE) for students at tertiary level so that they individualize the learning experience, has been a goal of a number of researchers (Eklund \& Brusilovsky, 1998; Kurzel, Slay, \& Hagenus, 2003; Martinez, 2001a; Sampson, Karagiannidis, \& Kinshuk, 2002; Voigt, 2003). A Learning Management System (LMS) that delivers the materials in these systems, typically attempts to tailor the LE to the individual based on profiling information that it maintains about the learner.

This tailoring can impact on the:

- content that is accessed and the media forms used in its representation

- groupings of the content and the relationships between them

- method of instruction employed

Material published as part of this journal, either on-line or in print, is copyrighted by Informing Science. Permission to make digital or paper copy of part or all of these works for personal or classroom use is granted without fee provided that the copies are not made or distributed for profit or commercial advantage AND that copies 1) bear this notice in full and 2) give the full citation on the first page. It is permissible to abstract these works so long as credit is given. To copy in all other cases or to republish or to post on a server or to redistribute to lists requires specific permission from the publisher at Publisher@InformingScience.org
- interactions that the students have with tutors and other students

- computer interface that the student interacts with and customizes 
- where and how the materials are accessed.

Tertiary institutions generally use the World Wide Web (WWW) to either support face to face instruction by maintaining resources, or indeed, as the main form of interaction when courses are administered solely online. This has enabled students to access course materials at home as they might at a university computer pool or library. Wireless networks provide the further flexibility of extending this connectivity to mobile devices (Brusilovsky, 2000). This infrastructure has enabled the provision of both the hypertextually linked educational artifacts and the student information supporting the delivery of the instruction. The overlaying of student and course information, provides the foundation for customized learning.

Earlier work (Eklund \& Brusilovsky, 1998; Kurzel, Slay, \& Chau, 2002; Slay, Quirchmayr, Kurzel, \& Hagenus, 2003) discussed how the WWW and Adaptive Hypermedia (AH) had the potential to individualise instruction in higher education. Interbook (Brusilovsky, Schwarz \& Weber, 1996) for example, demonstrated personalizing features that could account for individual differences in knowledge. Brusilovsky used the term concept when referring to the elementary pieces of knowledge within a domain.

This notion of a concept as a fundamental unit has subsequently been employed in instructional systems. It corresponds to a Sharable Content Object (SCO) as specified with the SCORM standard (SCORM 2003); SCOs are fine grained learning resources that are considered instructionally inert. In some domains i.e. information technology, it is also appropriate to further type these concepts as either declarative where fine grained course knowledge is espoused, or practical, where associated practical tasks are described and linked to the declarative concepts.

Take the example of a loop in a programming sense; the general structure, semantics and syntax of the loop can be declared in a concept but loop termination and the use of the loop variable, may be actions that are demonstrated practically. These concepts could also exist in a range of media formats with the LMS being able to display them. A practical task might be best represented as a short video but might have alternate representations that the students can choose between. Nevertheless, they constitute learning objects as defined by IEEE Learning technology Standards Committee specification.

The semantic links (pre-requisite, is-a-practical etc.) between concepts add low level instructional significance to the concepts within the domain. However, other Instructional Objects (IOs) are required to either aggregate concepts for delivery purposes, or provide templates that outline some instructional phase within the methodology being employed. These IOs then need to be mapped to a phase (Allert, Dhraief, \& Nejdl, 2002) within some instructional methodology.

Within this paper, I describe a framework in which the course instructional methodology can be altered to either suit the student, or the instructor. Further, I review and discuss other features that can be customized within a LE.

\section{The Domain and Learning Environment}

The domain for this research is the instructional content associated within the multimedia area where Macromedia Director is used as the main development environment. Multimedia Concepts is an introductory course that is followed by a more advanced level three course called Creating Interactive Multimedia.

The aim of the latter course as the name suggests, is to provide students with a major group project to complete, demonstrating a range of skills/features including:

- the ability to think creativity 
- interface, navigational and interactive design

- the documentation of designs

- the collective implementation and testing of the project artifacts.

Within this framework, issues addressing accessibility, navigational support, content management, use of the WWW, instructional design, etc. are included. Students taking this course come into it with a range of skills and find themselves undertaking particular roles within the group, depending of their areas of expertise. The pre-requisite of this course, Multimedia Concepts provides the foundational knowledge and skills required to create and utilize a range of media items within Director based, multimedia presentations.

An Adaptive Multimedia Learning Environment (AMLE) has been developed as a Personalized Learning Environment (PLE) for the presentation of these courses. A unique feature of the main interface within the architecture (Figure 1) is that it has been implemented in Macromedia Director, the main development environment; as a result, students can add to and modify the interface as required.

The course model for this information technology related area is organized hierarchically into

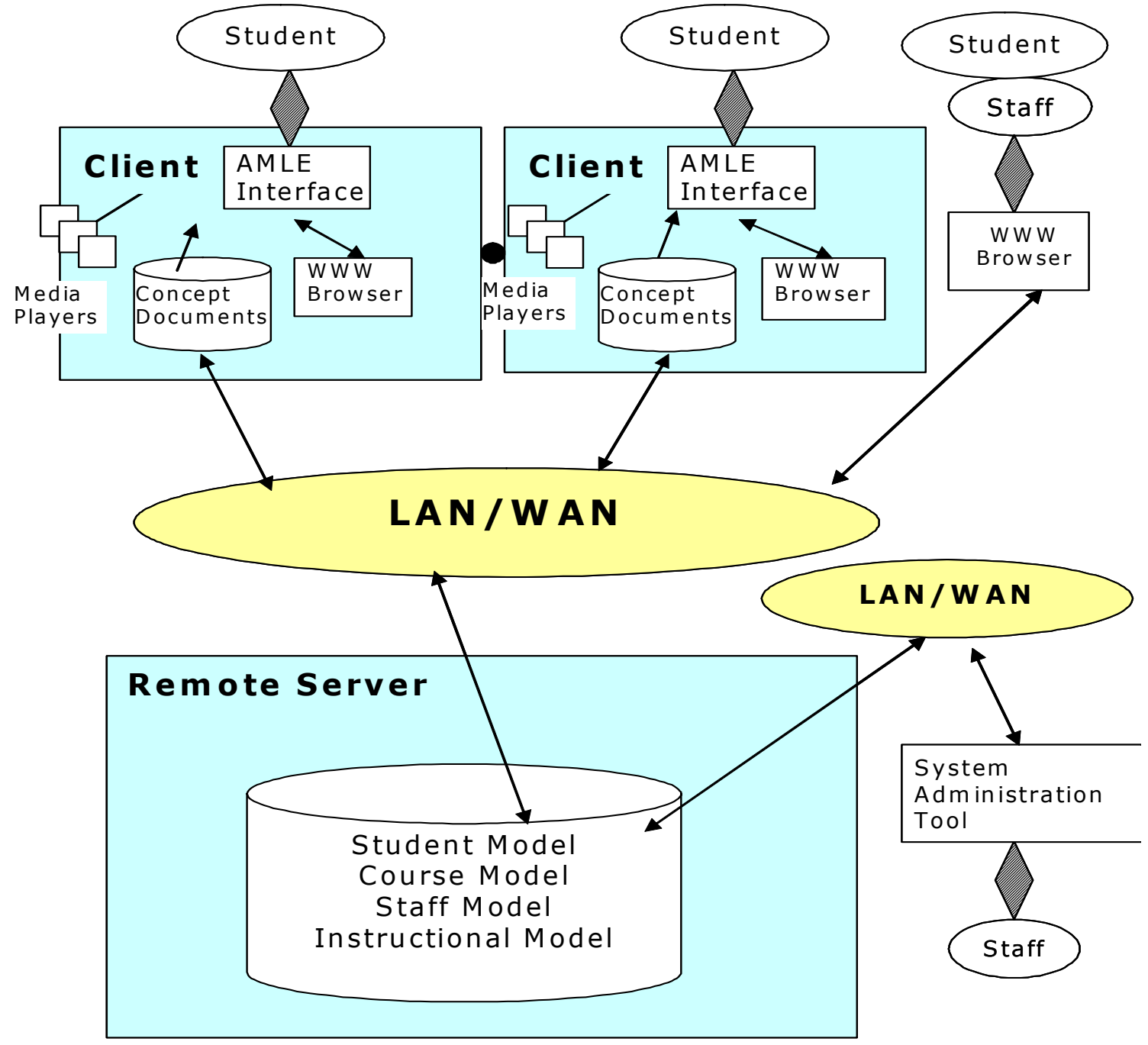

Figure 1: PLE A rchitecture 
courses, instructional objects, concepts and examples. Concepts can be either declarative or practical in nature. In a standard form of delivery, instructor organized groupings of content or sessions within the domain model (Figure 2) with their linked practical concepts, are presented to students. These sessions or groupings constitute a week's worth of work and are considered instructional objects; their aggregation and ordering have instructional significance.

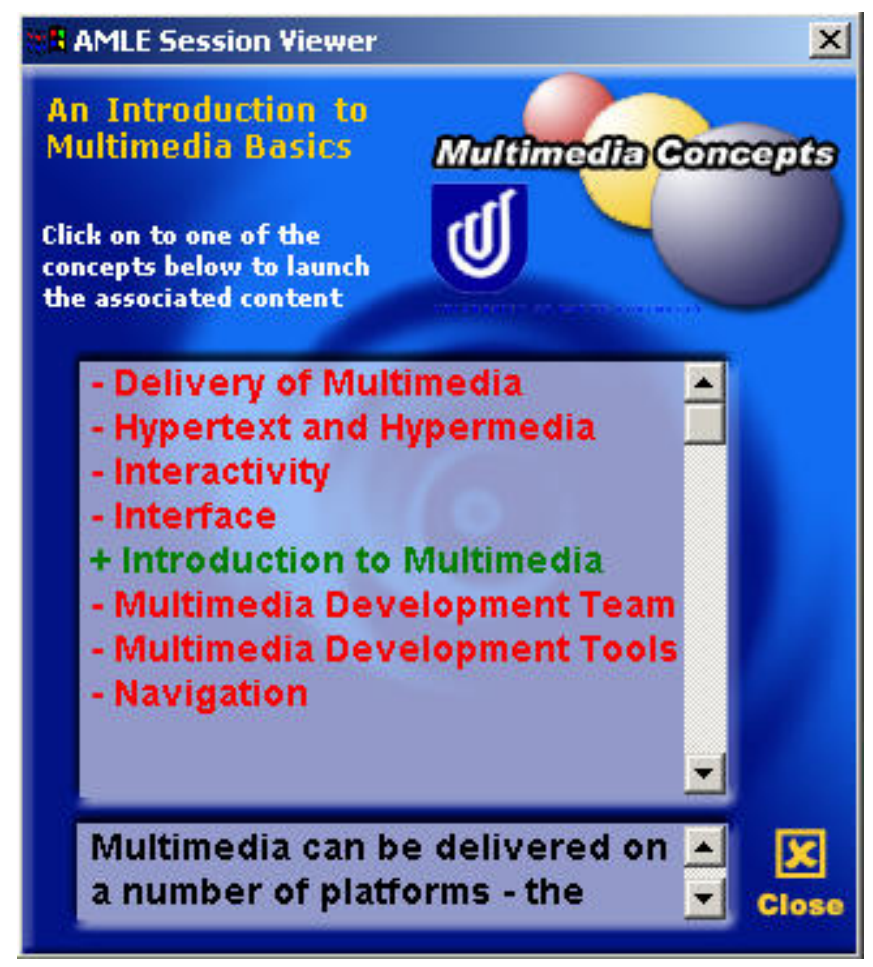

Figure 2: Session Viewer

JointZone $\odot(\mathrm{Ng}$, Maier, \& Hall, 2002) utilized both declarative and procedural knowledge in a hypermedia learning environment that provided adaptive case studies to medical students. Mullier inserted tutorials into the semantic network making up Hypernet (Mullier \& Dixon, 2000) to provide the students with tutorial tasks to reinforce learning.

It has been argued that link annotation (Brusilovsky et al., 1998) enables the user to make a more informed decision about the concept to pursue. Annotations within the session viewer are employed to indicate the content that a mouse click will provide. Where the system can infer that the student knows the concept (through previous responses to questions/quizzes) or can perform the task, the session viewer is annotated accordingly.

Links are not hidden so that the student is still able to follow it for revision purposes if required. Following a link activates the concept viewer which displays the concept in the different media forms that it might exist in. For example, a practical concept might exist in both textual and video formats; the latter might be more appropriate for some students.

Information Technology based domains are ideally suited for constructivist LEs because authentic activities are generally emphasized. Students are placed in real-world situations to acquire the knowledge and skills required by practitioners.

Sessions for the course Creating Interactive multimedia include:

- the development process

- the creative process 
- interactivity

- instructional design

- interface design and creation

- data representation

- navigational support

All sessions would contain both declarative and practical components, along with the project tasks and any other assessment components. This methodology could best be described as expository (Allert et al,, 2002).

Alternately, another instructional methodology might be to base instruction on a major project and administer the instruction in a more student oriented way. In a Problem Based Learning (PBL) scenario, a student would be presented with links to all the appropriate artifacts specified to support the different roles within this methodology. An instructional object might simply be an document that plays a role in the methodology; for example, it might be the specification of a problem.

Further elaboration of the phases (Allert et al., 2002) in this instructional orientation include the:

- presentation of the problem to be solved

- specification of the criteria the solution should meet

- background knowledge

- generation of ideas

- implementation of the solution

- evaluation of the solution

- conceptualization, integration and generalization of knowledge.

The content as specified in the expository methodology would manifest itself somewhere within each of these phases. For example, content associated with the techniques required to provide navigational support would constitute some background knowledge on navigation This might involve other instructional items like practical and other concepts that had been specified.

A course then might be presented by the instructor in different ways e.g. Creating Interactive Multimedia - PBL, or Creating Interactive Multimedia - Expository. Alternately, the student may opt to pursue a particular instructional orientation with the LMS providing access to the resources either through instructional objects, or through the use of tools like search engines, glossaries and concept maps that are provided to allow the students to locate content. Book marking (Figure 3) is also employed to allow the student to create their own view of the content and break away from the instructor's perspective.

Summarizing, the LE is a three tier system where fine grained, annotated declarative and practical concepts, form a semantic network of content. Instructional objects like sessions, practicals, assignments, problems, etc. then aggregate, utilize or account for the content. The instructional methodology then determines how these instructional objects are used in the instructional process. The methodology is specified within the instructional model and can be activated in the learning environment by the instructor, or the student. 


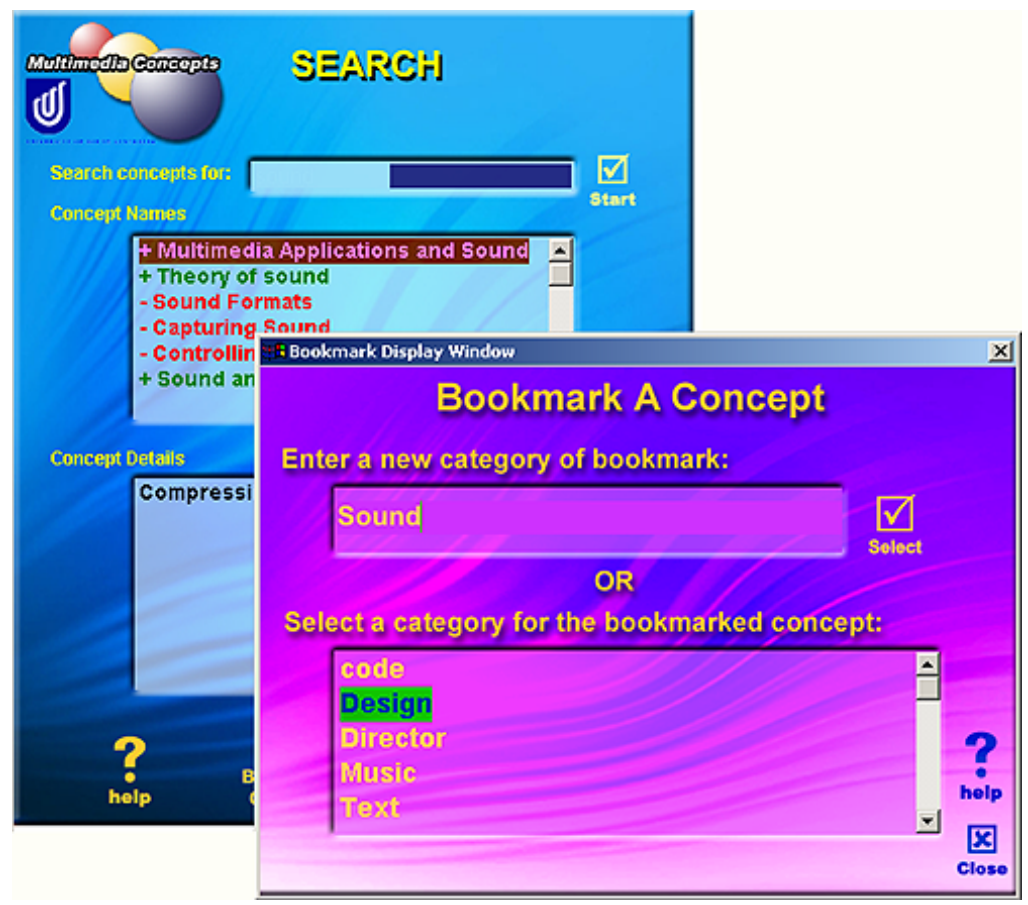

Figure 3: Search and book marking tools

\section{Customizable Characteristics}

From a student's perspective, a LE should support the way that they like to learn in:

- the method the materials are delivered and accessed

- the format that they exist in

- and the instructional methodology that underlies the course.

Further, it should account for the preferred learning styles of the students as they work within the environment. Martinez's (2001b) holistic approach describes the characteristics of different learning orientations and suggests strategies to support these within the LE. Voigt and Swatman (Voigt \& Swatman, 2003) emphasize the need for the learner to play a more fundamental role in the learning process and choose the methodology and resources that best suits their orientation. The environment then is customized and individually adaptable (Oppermann, Rashev, \& Kinshuk, 1997).

A distinction here is made between customizing the LE where the learner is an active participant in the decision making process, and personalizing, where the system uses profiling data predominantly to alter the view.

\section{Content}

Students generally undertake a course after completing the pre-requisites for it. However, this pre-requisite knowledge should still be available for the student to view if the latter course is based upon it. These 'completed' concepts the student has demonstrated competency with, and the components of the new course, can be annotated (Brusilovsky, 2000) to provide each student with a unique view of the proposed content. Links allow an individualized traversal of the semantic network of concepts that represent the domain knowledge. 
Researchers (Alty, 2002) correlated learning styles (Felder, 1993) and multimedia forms to support the notion that students might want to decide on different multimedia presentation formats; dual coding theory would support this assertion. Having multiple media formats of documents, customizes delivery in the sense that the student may have a media preference; certainly it might be argued that some practical concepts are best accounted for as video clips e.g scanning an image.

In IT related instructional environments, students can create a range of multimedia and hypermedia artifacts to satisfy the requirements of the course, or to simply satisfy their own individual needs e.g. creating their own media players. Jonassen, Peck, and Wilson (1999) suggest that the true worth of multimedia and hypermedia might be obtained through the learner constructing knowledge via the use of technology.

\section{Individualizing Content Groupings}

Previous work (Kurzel et al., 2002, 2003) has discussed how instructor organized groupings of content within the domain model may not necessarily meet the goals of the student, nor may they meet the student's view of the content. Providing tools in the LE to group concepts, allows students to establish their own structures of information. Book marking is an effective way of aggregating concepts within LEs. However, the original instructor generated course model provides the scaffolding for some learner orientations to fall back on.

The instructor too, is often forced into a particular methodology because of the tight coupling of instructional model with the domain model. With a separation of the domain model from the instructional model, this nexus is broken; the instructional model then needs to provide the mechanisms for defining not only the sequence that the learning resources are to be presented to the user, but the additional instructional resources that might support the methodology being employed.

\section{Personalized Interactions}

The students need access to all of the information about both their interaction with the course content and their progress through it. Tutors too need convenient access to the central repository of both course and student information. A range of reporting mechanisms need to be available for both students and instructors to display relevant information. Other communication facilities should also exit to allow on-line students within practical activities to discuss problems, or to simply discuss particular content-based issues.

Students might want to customize the student groupings and activate them when they are logged onto the system. To support this, these groupings have to be enumerated in the student models. In an online environment, students should be able to choose the tutor they work with and seek help from. Further, the learning environment should be able to provide both synchronous and asynchronous interactions to enable a variety of forms of interaction.

\section{Customizing the Interface}

Customizing the interface can at its simplest level refer to accessibility issues like the changing colours, fonts, backgrounds etc. Accessible web content and the use of portable document format (pdf) files with automated text/speech conversion account for some textual features; media controls in the interface account for sounds. This customization is not insignificant because it provides the users with an individual platform to work within; there is an ownership aspect to the interface. 
This can also include the use of tools that allow the user to incorporate their own reflections on particular educational items, and possibly include their own content representations. These could be textual or indeed aural. This extends the notion of accessibility within the interface and fosters the notion of customization and ownership of the LE. The notion of ownership of the interface can be extended either further through the creation of hypermedia artifacts as part of the course work, or as a result of personal interest.

It can be seen that IT related areas are well served by these notions and there is a good match between these areas of endeavor. Constructivist principles (Jonassen et al., 1997) involve students actively participating in the learning process, creating items and placing them into their workspace or on the WWW, searching out content and skills, and satisfying authentic tasks.

\section{Conclusion}

Major efforts have been directed at creating an adaptive and adaptable hypermedia/multimedia learning environment that provides students with customization features that hopefully enable a better fit with their learning needs. A learning environment has been established that adapts to prior knowledge through the use of link annotations; both declarative and practical concepts make up the domain.

The metadata supporting alternate instructional methodologies has been embedded in the learning environment to support automation within the learning management system. This metadata is based on the roles particular instructional objects play within the methodology of choice. Instructional objects might for example,

- aggregate a number of concepts into a session

- constitute a practical session or task that accounts for some practical concepts

- or simply specify the problem to be satisfied.

We continue to investigate constructivist principles within IT related course work and actively engage students with non-trivial problems. They work collaboratively in student centred ways to satisfy these tasks.

A range of concept viewers have been created to access the course model and a number of players/tools have been created to display and search for multimedia/hypermedia content. This content could be stored locally, or somewhere on the World Wide Web.

A trial of the environment evaluating the system's ability to manage different instructional methodologies will be conducted and reported upon. So too will be the perceived effectiveness of the other customizing features discussed in this paper.

\section{References}

Allert, H., Dhraief, H, \& Nejdl, W. (2002). Meta-level category 'role' in metadata standards for learning: instructional roles and instructional qualities of learning objects. Proceedings of the CosignConference.

Brusilovsky, P. (2000). Adaptive hypermedia: From intelligent tutoring systems to web-based education. intelligent tutoring systems. Montreal, Canada: Springer-Verlag.

Brusilovsky, P., Schwarz, E., \& Weber, G. (1996). A tool for developing adaptive electronic textbooks on the WWW. Proceedings of WebNet'96, World Conference of the Web Society, San Francisco, CA. 
Eklund, J. \& Brusilovsky, P. (1998). The value of adaptivity in hypermedia learning environmnet: A short review of emperical evidence. Workshop on Adaptive Hypertext and Hypermedia - HYPERTEXT 98:, Pittsburgh, PA, USA.

Felder, R. (1993). Reaching the second tier: Learning and teaching in college science education. Journal of College Science Teaching, 23(5), 286-290.

Jonassen, D., Peck, K. \& Wilson, B. (1999). Learning with technology: A constructivist perspective. Upper Saddle, NJ: Merrill, Prentice Hall.

Jonassen, D. H., Dyer, D., Peters, K., Robinson, T., Harvey, D., King, M., \& Loughner, P. (1997). Cognitive flexibility hypertexts on the Web: Engaging learners in meaning making. In B. Kahn, Web-based Instruction (pp 119-134). Englewood Cliffs, NJ: Educational Technology Publications.

Kurzel, F., Slay, J. \& Chau, Y. H. (2002). Towards an adaptive multimedia learning environment: Enhancing the student experience. ED-MEDIA2002, Denver, Colorada, AACE.

Kurzel, F. Slay, J. \& Hagenus, K. (2003). Personalising the learning environment. Proceedings of the Informorming Science and Information Technology Education Conference, Pori, Finland.

Martinez, M. (2001a). Foundations for personalised Web learning environments. Journal of Asynchronous Learning Networks, 4(2).

Martinez, M. (2001b). Key design considerations for personalised learning on the Web. Educational Technology \& Society 4(1), 26-40.

Ng, M. H., Maier, P. \& Hall, W. (2002). Making web-based learning adaptive. Proceedings of InSITE2002, Cork, Ireland.

Oppermann, R., Rashev, R., \& Kinshuk, Ed. (1997). Adaptability and Adaptivity in Learning Systems. London, UK: Knowledge Transfer.

Sampson, D., Karagiannidis, C. \& Kinshuk (2002). Personalising learning: Educational, technogical and standardisation perspective. Interactice Educational Multimedia 4, 24-39.

SCORM (2003). Sharable Content Object Reference Model (SCORM) 1.2.

Slay, J., Quirchmayr, G., Kurzel, F. \& Hagenus, K. (2003). Adaptive learning environments for CS education - From AMLE to live spaces. ACE2003, Adelaide, South Australia, Australia, Conferences in Research and Practice in Information Technology,

Voigt, C. \& Swatman., P. M. C. (2003). Learning to learn: HCI-methods for personalised eLearning. 10th International Conference on Human-Computer Interaction, Crete, Greece.

\section{Biography}

Frank Kurzel is a lecturer in the School of Communication, Information and New Media of the University of South Australia. He has been the Program Director for the Multimedia Studies Major within the Bachelor of Arts program at the University of South Australia. He has had extensive experience in Education, Computer Science and Multimedia areas. His research interests include web-based instructional systems to support his teaching, and the integration of Intelligent Tutoring Systems technology into hypermedia environments. He is also interested in instructional methodologies and enhancing the educational environment. 